\title{
Efficacy of fimasartan/hydrochlorothiazide combination in hypertensive patients inadequately controlled by fimasartan monotherapy
}

This article was published in the following Dove Press journal:

Drug Design, Development and Therapy

2 June 2015

Number of times this article has been viewed

Moo-Yong Rhee,' Sang Hong Baek, ${ }^{2}$ Weon Kim, ${ }^{3}$ Chang Gyu Park, ${ }^{4}$ Seung Woo Park, ${ }^{5}$ ByungHee Oh, ${ }^{6}$ Sang-Hyun Kim, ${ }^{7}$ Jae-Joong Kim, ${ }^{8}$ Joon-Han Shin, ${ }^{9}$ Byung-Su Yoo, ${ }^{10} \mathrm{Se}-J o o n g ~ R i m,{ }^{\prime \prime}$ Jong-Won $\mathrm{Ha},{ }^{12}$ Joon Hyung Doh, ${ }^{13}$ Youngkeun Ahn, ${ }^{14}$ Jei Keon Chae, ${ }^{15}$ Jeong Bae Park, ${ }^{16}$ Soon-Kil Kim, ${ }^{17}$ Cheol Ho Kim ${ }^{18}$

'Cardiovascular Center, Dongguk University Ilsan Hospital, Goyang, ${ }^{2}$ Catholic University of Korea, Seoul St Mary's Hospital, Seoul, ${ }^{3}$ Cardiovascular Department of Internal Medicine, Kyung Hee University Medical Center, Seoul, ${ }^{4}$ Division of Cardiology, Guro Hospital, Korea University College of Medicine, Seoul, ${ }^{5}$ Division of Cardiology, Samsung Medical Center, Seoul, ${ }^{6}$ Department of Internal Medicine, Seoul National University Hospital, Seoul, ' Division of Cardiology, Seoul Metropolitan Government Seoul National University Boramae Medical Center, Seoul, ${ }^{8}$ Division of Cardiology, Asan Medical Center, Seoul, ${ }^{9}$ Division of Cardiology, Ajou University Hospital, Suwon, ${ }^{\circ}$ Division of Cardiology,

Wonju Severance Christian Hospital, Wonju,

"Division of Cardiology, GangNam Severance Hospital, Seoul, '2Division of Cardiology, Severance Hospital, Seoul, ${ }^{13}$ Division of Cardiology, Inje University llsan Hospital, Goyang, ${ }^{14}$ Department of Cardiology, Chonnam National University Hospital, Gwangju, ${ }^{15}$ Chonbuk National University Hospital, Jeonju, ${ }^{16}$ Department of Cardiology, Cheil General Hospital, Dankook University College of Medicine, Seoul, ${ }^{17}$ Department of Cardiology, Hanyang University Guri Hospital, Guri, ${ }^{18}$ Department of Internal Medicine, Seoul National University Bundang Hospital, Seongnam, Republic of Korea

Correspondence: Cheol Ho Kim

Department of Internal Medicine, Seoul National University College of Medicine, Seoul National University Bundang Hospital, Gumi-ro I73,

Bundang-gu, Seongnam-si, Gyeonggi-do 463-707, Republic of Korea

$\mathrm{Tel}+82317877001$

Fax +82 3I 7874052

Email cheolkim@snu.ac.kr
Background: The study reported here compared the blood pressure (BP)-lowering efficacy of fimasartan alone with that of fimasartan/hydrochlorothiazide (HCTZ) combination in patients whose BP goal was not achieved after 4 weeks of treatment with once-daily fimasartan $60 \mathrm{mg}$.

Methods: Patients with sitting diastolic blood pressure (siDBP) $\geq 90 \mathrm{mmHg}$ with 4 weeks of once-daily fimasartan $60 \mathrm{mg}$ were randomly assigned to receive either once-daily fimasartan $60 \mathrm{mg} / \mathrm{HCTZ} 12.5 \mathrm{mg}$ or fimasartan $60 \mathrm{mg}$ for 4 weeks. After 4 weeks, the dose was increased from fimasartan $60 \mathrm{mg} / \mathrm{HCTZ} 12.5 \mathrm{mg}$ to fimasartan $120 \mathrm{mg} / \mathrm{HCTZ} 12.5 \mathrm{mg}$ or from fimasartan $60 \mathrm{mg}$ to fimasartan $120 \mathrm{mg}$ if siDBP was $\geq 90 \mathrm{mmHg}$.

Results: Of the 263 randomized patients, 256 patients who had available efficacy data were analyzed. The fimasartan/HCTZ treatment group showed a greater reduction of siDBP compared to the fimasartan treatment group at Week $4(6.88 \pm 8.10 \mathrm{mmHg}$ vs $3.38 \pm 7.33, P=0.0008)$, and the effect persisted at Week $8(8.67 \pm 9.39 \mathrm{mmHg}$ vs $5.02 \pm 8.27 \mathrm{mmHg}, P=0.0023)$. Reduction of sitting systolic BP in the fimasartan/HCTZ treatment group was also greater than that in the fimasartan treatment group (at Week $4,10.50 \pm 13.76 \mathrm{mmHg}$ vs $5.75 \pm 12.18 \mathrm{mmHg}, P=0.0069$ and, at Week $8,13.45 \pm 15.15 \mathrm{mmHg}$ vs $6.84 \pm 13.57 \mathrm{mmHg}, P=0.0007)$. The proportion of patients who achieved a reduction of siDBP $\geq 10 \mathrm{mmHg}$ from baseline and/or a mean siDBP $<90 \mathrm{mmHg}$ after 4 weeks of treatment was higher in the fimasartan/HCTZ treatment group than in the fimasartan treatment group (53.6\% vs $39.8 \%, P=0.0359)$. The overall incidence of adverse drug reaction was $11.79 \%$ with no significant difference between the treatment groups.

Conclusion: The combination treatment of fimasartan and HCTZ achieved better BP control than fimasartan monotherapy, and had comparable safety and tolerance to fimasartan monotherapy. Keywords: blood pressure, antihypertensive, angiotensin-converting enzyme inhibitor, angiotensin-receptor blocker, angiotensin II type 1 receptor, renin-angiotensin-aldosterone system inhibitor

\section{Introduction}

Hypertension is a major independent risk factor for coronary artery disease, stroke, and renal failure. Reducing blood pressure (BP) below the target goal is important to prevent cardiovascular and cerebrovascular events. ${ }^{1}$ Various kinds of antihypertensive drugs such as diuretics, calcium channel blockers, beta blockers, angiotensin-converting enzyme (ACE) inhibitors, and angiotensin-receptor blockers (ARBs) have been used to lower BP effectively. Fimasartan is a new antihypertensive drug that lowers BP by blocking the angiotensin II type 1 receptor. ${ }^{2}$ The efficacy of fimasartan in reducing office-measured BP was shown to be greater than that of losartan. ${ }^{3}$ Maintenance of 24-hour BP reduction by fimasartan was comparable to or slightly better than by 
valsartan. ${ }^{4}$ The safety profile of fimasartan was also similar to losartan and valsartan..$^{3,4}$

Despite the availability of various antihypertensive drugs, achieving target BP is difficult in the majority of patients with hypertension, although the control rate is improving. ${ }^{5,6}$ Most patients require a combination of two or more drugs to achieve their target BP because effective BP reduction is difficult with monotherapy. ${ }^{7}$ The drug commonly used in combination with ARBs is hydrochlorothiazide (HCTZ). Several studies have demonstrated enhanced BP reduction with combinations of a renin-angiotensin-aldosterone system (RAAS) inhibitor and HCTZ compared to either treatment alone..$^{8-10}$ Because administration of HCTZ alone reduces plasma volume and activates the RAAS, ${ }^{11}$ the addition of a RAAS inhibitor to HCTZ may offset the diuretic-induced increase in plasma renin activity and could theoretically attenuate the metabolic effects of HCTZ.

The primary purpose of the study reported here was to compare the BP-lowering efficacy of fimasartan alone with that of fimasartan/HCTZ combination treatment in patients whose BP goal was not achieved after 4 weeks of treatment with once-daily fimasartan $60 \mathrm{mg}$.

\section{Methods}

\section{Patients}

Male and female patients aged 18 years and above were enrolled in the study if they met the following criteria: on the screening visit, mean values of two sitting diastolic blood pressure (siDBP) readings had to be $<110 \mathrm{mmHg}$ if the patient were on antihypertensive medication; if the patient were antihypertensive naïve, the mean values of two siDBP readings had to be $\geq 90 \mathrm{mmHg}$ and $<120 \mathrm{mmHg}$. Patients were excluded if they had: a mean sitting systolic blood pressure (siSBP) $\geq 200 \mathrm{mmHg}$ at the screening visit; a difference of siSBP $\geq 20 \mathrm{mmHg}$ or siDBP $\geq 10 \mathrm{mmHg}$ between arms; secondary hypertension (ie, renovascular hypertension, endocrinologic disease, and use of hormonal contraceptives or drugs affecting BP); hepatic (aspartate transaminase and alanine transaminase $\geq 2.0 \times$ upper limit of normal) or renal impairment (serum creatinine $\geq 1.5 \times$ upper limit of normal); active hepatitis B or C (including carriers); positive status for HIV; known allergy to the study drugs; a sodium $(<133 \mathrm{mmol} / \mathrm{L}$ or $\geq 145 \mathrm{mmol} / \mathrm{L})$ or potassium ( $<3.5 \mathrm{mmol} / \mathrm{L}$ or $\geq 5.5 \mathrm{mmol} / \mathrm{L})$ electrolyte imbalance; insulin-dependent or uncontrolled diabetes mellitus (glycated hemoglobin $\left[\mathrm{HbA}_{1 \mathrm{C}}\right]>9 \%$ ); retinal hemorrhage or exudates within the previous 6 months; drug or alcohol dependency; heart or cerebrovascular disease within the previous 6 months (coronary heart disease, heart failure, significant valvular heart disease, cerebral infarction, or cerebral hemorrhage); active inflammatory gastrointestinal disease in the preceding 12 months or a history of gastrointestinal surgery or disease that could interfere with drug absorption; or the presence of a wasting disorder, autoimmune disease, or connective tissue disease. Women who were pregnant, breastfeeding, or those with child-bearing potential who were not sterilized and had no intention of using a contraceptive were also excluded.

\section{Study design}

The study was conducted at 18 institutions in Korea as a multicenter, randomized, active-controlled, double-blind, parallel-group, dose-titration trial. The study design was approved by the Korea Food and Drug Administration and the institutional review board of each site. After screening, patients who met the eligibility criteria were given once-daily fimasartan $60 \mathrm{mg}$ for 4 weeks. Patients already receiving antihypertensive therapy discontinued taking their previously prescribed drugs and were directly rolled into once-daily fimasartan $60 \mathrm{mg}$ without a washout period. After 4 weeks of treatment with once-daily fimasartan $60 \mathrm{mg}$, patients with siDBP $\geq 90 \mathrm{mmHg}$ were randomly assigned to receive either once-daily fimasartan $60 \mathrm{mg} / \mathrm{HCTZ} 12.5 \mathrm{mg}$ or fimasartan $60 \mathrm{mg}$ for 4 weeks at a 2:1 ratio by using sealed envelopes with the randomization number. The dose of the study drug was increased to fimasartan $120 \mathrm{mg} / \mathrm{HCTZ} 12.5 \mathrm{mg}$ or fimasartan $120 \mathrm{mg}$ then maintained for another 4 weeks if the siDBP was still $>90 \mathrm{mmHg}$ after 4 weeks of treatment with fimasartan $60 \mathrm{mg} / \mathrm{HCTZ} 12.5 \mathrm{mg}$ and fimasartan $60 \mathrm{mg}$. The study-drug dose was maintained in patients whose siDBP was $<90 \mathrm{mmHg}$.

All patients were instructed to take the study drug once daily between 6 am and 10 am for the study duration. Patients were instructed to fast for 12 hours prior to the scheduled visit and to refrain from taking the study medication in the morning before trough BP measurement. At each visit, after at least 5 minutes of rest in a sitting position, siSBP, siDBP, and pulse rate were measured twice with a 1-minute interval between measurements in the same arm using a semiautomated sphygmomanometer (HEM-7080IT [equivalent to 705IT], Omron Corporation, Kyoto, Japan). ${ }^{12}$ The average of the two sitting BP measurements was used. All adverse events were evaluated and recorded at each visit.

\section{Efficacy evaluation}

This study was designed to compare the antihypertensive efficacy of fimasartan $60 \mathrm{mg} / \mathrm{HCTZ} 12.5 \mathrm{mg}$ combination 
treatment to that of treatment with fimasartan $60 \mathrm{mg}$ alone in patients who did not achieve the target BP after 4 weeks of treatment with fimasartan $60 \mathrm{mg}$.

The primary goal of this study was to compare the changes in mean siDBP from the baseline to Week 4 of treatment with the study drug (fimasartan $60 \mathrm{mg} / \mathrm{HCTZ} 12.5 \mathrm{mg}$ ) and the control drug (fimasartan $60 \mathrm{mg}$ ) in patients who did not achieve target siDBP after 4 weeks of prior treatment with once-daily fimasartan $60 \mathrm{mg}$.

The secondary efficacy points were: (1) change of mean siSBP from baseline at 4 and 8 weeks; (2) BP control rate (a proportion of patients who achieved mean siDBP $<90 \mathrm{mmHg}$ ) and response rate (a proportion of patients who achieved a reduction of siDBP $\geq 10 \mathrm{mmHg}$ from baseline and/or a mean siDBP $<90 \mathrm{mmHg}$ ) at 4 and 8 weeks; and (3) change of mean siDBP from baseline at 8 weeks.

\section{Safety evaluation}

Safety and tolerability were assessed at each visit by physical examination, direct questioning, and clinical laboratory test. Blood and urine samples were collected for laboratory tests at baseline, Week 4, and Week 8. Electrocardiography was performed at screening and at the end of the study. All adverse events that occurred during the study and details of their nature, occurrence, and elimination date, duration, severity, significance, and the relationship with the study drug were recorded.

\section{Sample size}

To identify the primary hypothesis, we assumed a potential difference of $3 \mathrm{mmHg}$ in mean change of siDBP with a standard deviation of $7.5 \mathrm{mmHg}$ between the two therapies. ${ }^{3,13-19}$ With a randomization ratio of $2: 1$ between patients assigned fimasartan $60 \mathrm{mg} / \mathrm{HCTZ} 12.5 \mathrm{mg}$ and those assigned fimasartan $60 \mathrm{mg}$, significance level of $5 \%$, and statistical power of $80 \%$, the total number of required subjects was 225 (150 for fimasartan $60 \mathrm{mg} / \mathrm{HCTZ} 12.5 \mathrm{mg}$ and 75 for fimasartan $60 \mathrm{mg}$ ). Allowing for a drop-out rate of $10 \%$, the total number of subjects to be enrolled was estimated to be 250 (167 for the study drug and 83 for the control drug). The number of subjects required for screening, assuming a nonresponder rate of $50 \%$, was estimated to be approximately 500 .

\section{Statistical analyses}

For efficacy analysis, the intention-to-treat (ITT) analysis set was used for the main analysis while the per-protocol (PP) analysis set was additional. The ITT analysis set included all subjects with efficacy assessment variables for at least one time after randomization. Among the ITT population, the PP analysis set included subjects who completed the study without major or serious protocol violations. If any efficacy assessment variables were missed, they were imputed by the last-observation-carried-forward method. For safety analysis, we included all subjects who received the investigational drug at least once. Subjects who had been enrolled in the study but dropped out before drug administration were excluded. Safety assessment variables were not imputed for missed data.

The changes from baseline in siDBP and siSBP of the two groups at the end of 4 and 8 weeks of treatment were compared by two-sample $t$-test. In addition, we conducted analysis of covariance for changes of siDBP with baseline siDBP and investigation centers as covariates, and the two treatment groups as the factor. Descriptive statistics for the rates of the responders ( $\mathrm{siDBP}<90 \mathrm{mmHg}$ or siDBP reduction from the baseline $\geq 10 \mathrm{mmHg}$ ) and control subjects ( the differences between the two groups were analyzed by Pearson's chi-square.

Adverse events were coded using the Medical Dictionary for Regulatory Activities (MedDRA; v 13.0) and the percentage of the subjects who experienced any adverse events was determined. The chi-square test was also performed to analyze group differences. The incidence rates are presented by severity and causal relationship with each drug.

Demographic characteristics were compared between the two groups using the $t$-test or Wilcoxon rank-sum test for continuous variables and the chi-square test or Fisher's exact test for categorical variables. All data were analyzed using SAS ${ }^{\circledR}$ software (v 9.2; SAS Institute, Cary, NC, USA) and all tests were done at a significance level of 5\% using a two-sided test.

\section{Results \\ Patients' disposition}

Among 654 patients screened, 263 were matched to eligible randomization criteria after 4 weeks of treatment with once-daily fimasartan $60 \mathrm{mg}$. Of the 263 patients, 175 were assigned to 4 weeks of fimasartan/HTCZ treatment and 88 were assigned to 4 weeks of fimasartan treatment (Figure 1). Among the remaining 391 patients who were not randomized, 233 (59.6\%) had a diastolic BP <90 mmHg meeting the exclusion criterion of randomization. Thirty patients discontinued the study after randomization. Of these, six discontinued because of inclusion/exclusion deviation, 14 for consent withdrawal, five for adverse events, two for unsatisfactory responses, and three for other reasons. 


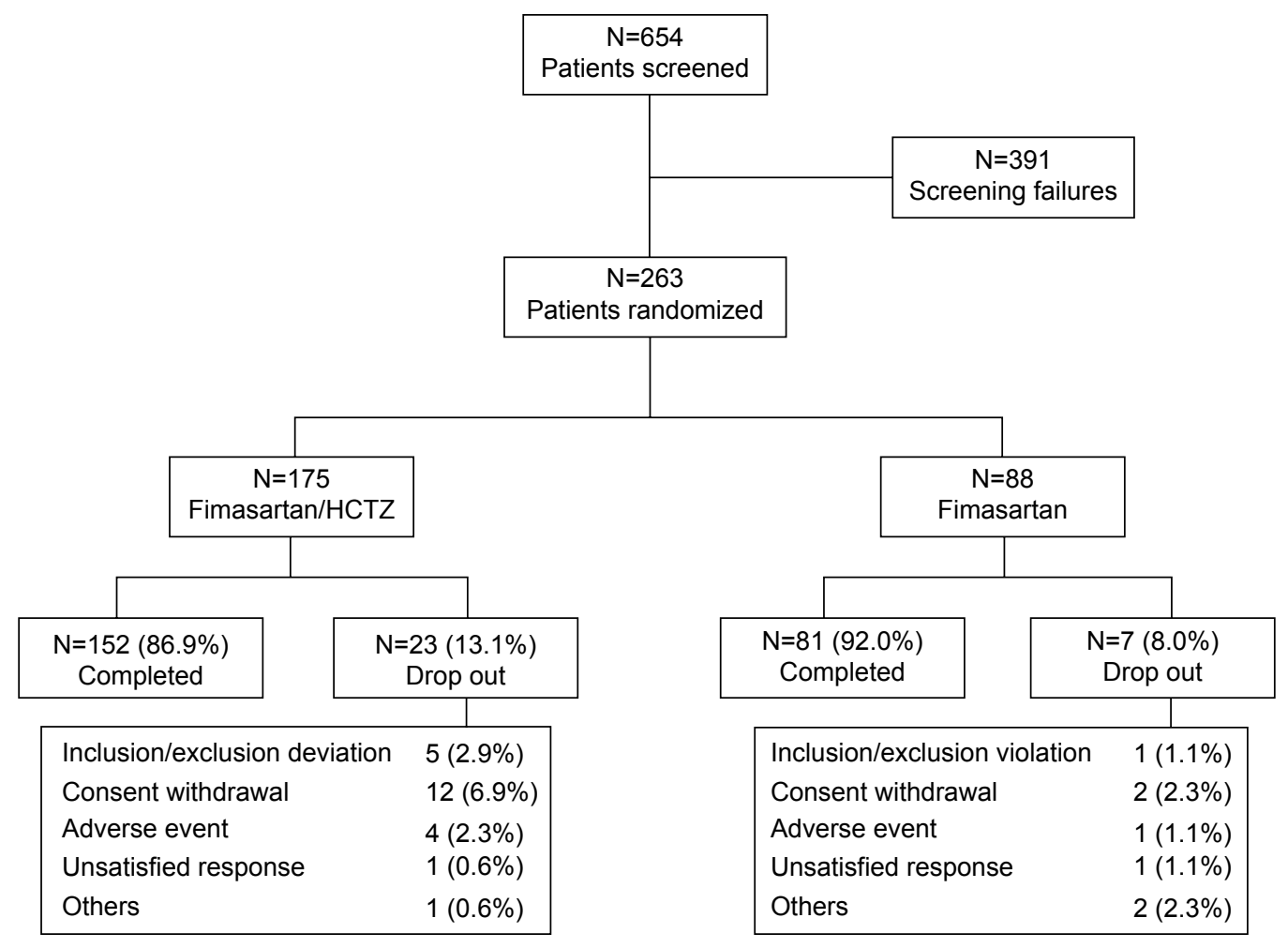

Figure I Subject disposition and reasons for drop out.

Abbreviation: HCTZ, hydrochlorothiazide.

Of the 263 patients, 256 were included in the primary efficacy analysis and seven were excluded because of missing efficacy data. There were no significant differences in baseline characteristics between the groups with the exception of the number of smokers (Table 1). The number of smokers was higher in the fimasartan/HCTZ group than in the fimasartan group. The mean age was $54.7 \pm 9.1$ years. The majority of patients were men (76.6\%). Among the prior medication taken by the patients, one had been on a cardiac drug (nicorandil), and another took a peripheral vasodilator (nicametate citrate). The baseline siDBP and siSBP were not different between the treatment groups $(P=0.7032$ and 0.4015 , respectively).

\section{Efficacy}

The means of trough siDBP and siSBP at baseline, Week 4, and Week 8 are presented in Table 2. The reduction of siDBP and siSBP was greater in the fimasartan/HCTZ group than in the fimasartan group. The reduction of siDBP was $6.88 \pm 8.10 \mathrm{mmHg}$ in the fimasartan/HCTZ group and $3.38 \pm 7.33 \mathrm{mmHg}$ in the fimasartan group at Week 4 $(P=0.0008)$. The difference in siDBP reduction between the treatment groups was $-3.35 \mathrm{mmHg}$ ( $95 \%$ confidence interval: -5.39 to $-1.32, P=0.0013$ by analysis of covariance).
At Week 8, the reduction in siDBP was $8.67 \pm 9.39 \mathrm{mmHg}$ in the fimasartan/HCTZ group and 5.02 $\pm 8.27 \mathrm{mmHg}$ in the fimasartan group $(P=0.0023)$. The reduction in siSBP was $10.50 \pm 13.76 \mathrm{mmHg}$ in the fimasartan/HCTZ group and $5.75 \pm 12.18 \mathrm{mmHg}$ in the fimasartan group at Week 4 $(P=0.0069)$. At Week 8 , the reduction in siSBP was $13.45 \pm 15.15 \mathrm{mmHg}$ in the fimasartan/HCTZ group and $6.84 \pm 13.57 \mathrm{mmHg}$ in the fimasartan group $(P=0.0007)$.

When the fimasartan dose of both treatment groups was increased to $120 \mathrm{mg}$ in patients who did not achieve the target $\operatorname{siDBP}(\geq 90 \mathrm{mmHg}$ ) at Week 4, siDBP and siSBP decreased significantly by Week 8 (Table 3). Although there was no statistical significance, the fimasartan/HCTZ group showed greater reduction of siDBP and siSBP compared to the fimasartan group. Reduction in siDBP was $5.72 \pm 9.34 \mathrm{mmHg}$ in the fimasartan/HCTZ group and 3.64 $\pm 6.97 \mathrm{mmHg}$ in the fimasartan group $(P=0.1922)$. Reduction in siSBP was $7.86 \pm 15.40 \mathrm{mmHg}$ in the fimasartan/HCTZ group and $4.45 \pm 11.45 \mathrm{mmHg}$ in the fimasartan group $(P=0.1943)$.

The responses and control rates are displayed in Figure 2. The response rate at Week 4 was $53.6 \%(90 / 168)$ in the fimasartan/HCTZ group and $39.8 \%(35 / 88)$ in the fimasartan group $(P=0.0359)$. At Week 8 , the response rate was $63.1 \%$ $(106 / 168)$ in the fimasartan/HCTZ group and $51.1 \%(45 / 88)$ 
Table I Baseline characteristics of study population

\begin{tabular}{|c|c|c|c|c|}
\hline Characteristic & $\begin{array}{l}\text { Fimasartan/HCTZ } \\
(\mathbf{N}=168)\end{array}$ & $\begin{array}{l}\text { Fimasartan } \\
(\mathbf{N}=\mathbf{8 8})\end{array}$ & $\begin{array}{l}\text { Total } \\
(\mathrm{N}=256)\end{array}$ & $P$-value* \\
\hline Age (years), mean (SD) & $55.3(9.40)$ & $53.4(8.20)$ & $54.7(9.10)$ & $0.1057^{\mathrm{a}}$ \\
\hline Weight (kg), mean (SD) & $71.9(9.70)$ & $71.3(9.10)$ & $71.7(9.50)$ & $0.6515^{a}$ \\
\hline Height $(\mathrm{cm})$, mean (SD) & $166.8(6.80)$ & $166.6(7.90)$ & $166.7(7.20)$ & $0.8069^{a}$ \\
\hline Sex, n (\%) & & & & $0.4607^{c}$ \\
\hline Male & $|3|(77.98)$ & $65(73.86)$ & $196(76.56)$ & \\
\hline Female & $37(22.02)$ & $23(26.14)$ & $60(23.44)$ & \\
\hline Smoking, n (\%) & & & & $0.0095^{c}$ \\
\hline Non-smoker & $77(45.83)$ & $48(54.55)$ & $125(48.83)$ & \\
\hline Past smoker & $44(26.19)$ & 30 (34.09) & $74(28.91)$ & \\
\hline Smoker & 47 (27.98) & $10(11.36)$ & $57(22.27)$ & \\
\hline Medication history, n (\%) & & & & $0.4739^{c}$ \\
\hline ACE inhibitors or $A R B s$ & 87 (51.79) & $52(59.09)$ & $139(54.30)$ & \\
\hline Calcium channel blockers & $71(42.26)$ & 31 (35.23) & $102(39.84)$ & \\
\hline Beta blockers & $24(14.29)$ & 17 (I9.32) & $4 \mid(16.02)$ & \\
\hline Diuretics & $16(9.52)$ & $9(10.23)$ & $25(9.77)$ & \\
\hline Lipid modifying agents & $3(1.79)$ & - & $3(1.17)$ & \\
\hline Alpha-blockers & I $(0.60)$ & - & I (0.39) & \\
\hline Cardiac drug & - & I (I.14) & I (0.39) & \\
\hline Peripheral vasodilators & I $(0.60)$ & - & I (0.39) & \\
\hline Drinking history, n (\%) & & & & $0.0625^{c}$ \\
\hline Non-drinker & $39(23.21)$ & 30 (34.09) & $69(26.95)$ & \\
\hline Drinker & $129(76.79)$ & $58(65.91)$ & $187(73.05)$ & \\
\hline Mean duration of hypertension, years (SD) & $6.20(6.02)$ & $6.59(5.84)$ & $6.33(5.95)$ & $0.4465^{\mathrm{b}}$ \\
\hline \multicolumn{5}{|l|}{ Baseline blood pressure, $\mathrm{mmHg}(\mathrm{SD})$} \\
\hline Diastolic & $96.8(5.70)$ & $96.5(5.40)$ & & $0.7078^{a}$ \\
\hline Systolic & $150.8(12.70)$ & $149.4(\mid 1.90)$ & & $0.3994^{\mathrm{a}}$ \\
\hline
\end{tabular}

Notes: *Difference between treatment groups by atwo-sample $t$-test, ${ }^{b}$ Wilcoxon rank-sum test, or chi-square test.

Abbreviations: ACE, angiotensin-converting enzyme; ARB, angiotensin-receptor blocker; HCTZ, hydrochlorothiazide; SD, standard deviation.

in the fimasartan group, which was not statistically different $(P=0.0647)$. In the PP analysis, the response rate of the fimasartan/HTCZ treatment group was higher than that of the fimasartan treatment group (at Week $4,55.7 \%$ vs $40.2 \%$, $P=0.0245$ and, at Week $8,67.1 \%$ vs $52.4 \%, P=0.0280$ ). Although there was no statistically significant difference, the fimasartan/HCTZ group had a higher control rate at Weeks 4 and 8.

\section{Safety and tolerability}

In the safety-analysis population, the incidence of adverse events considered to be at least partly related to the study

Table 2 Means of sitting diastolic and systolic blood pressure at Weeks 4 and 8

\begin{tabular}{|c|c|c|c|c|c|}
\hline Visit & $\begin{array}{l}\text { Fimasartan/HCTZ } \\
(\mathbf{N}=168)\end{array}$ & $\begin{array}{l}\text { Fimasartan } \\
(\mathbf{N}=\mathbf{8 8})\end{array}$ & $\begin{array}{l}\text { Difference in } \\
\text { change } \pm \text { SD }\end{array}$ & $\begin{array}{l}95 \% \text { confidence } \\
\text { interval }\end{array}$ & $P$-value* \\
\hline \multicolumn{6}{|c|}{ siDBP (mmHg) } \\
\hline Baseline & $96.81 \pm 5.65$ & $96.53 \pm 5.44$ & & & \\
\hline Week 4 & $89.93 \pm 9.14$ & $93.16 \pm 8.87$ & & & \\
\hline Change $^{\mathrm{a}}$ & $-6.88 \pm 8.10$ & $-3.38 \pm 7.33$ & $-3.50 \pm 7.84$ & $-5.53,-1.47$ & 0.0008 \\
\hline Week 8 & $88.14 \pm 9.65$ & $91.51 \pm 9.84$ & & & \\
\hline Change $^{b}$ & $-8.67 \pm 9.39$ & $-5.02 \pm 8.27$ & $-3.65 \pm 9.02$ & $-5.99,-|.3|$ & 0.0023 \\
\hline \multicolumn{6}{|c|}{ siSBP (mmHg) } \\
\hline Baseline & $150.77 \pm 12.65$ & $|49.40 \pm| \mid .87$ & & & \\
\hline Week 4 & $140.27 \pm 15.55$ & $143.65 \pm 14.76$ & & & \\
\hline Change $^{a}$ & $-10.50 \pm 13.76$ & $-5.75 \pm 12.18$ & $-4.75 \pm 13.24$ & $-8.18,-1.32$ & 0.0069 \\
\hline Week 8 & $137.32 \pm 15.90$ & $142.56 \pm 16.22$ & & & \\
\hline Change $^{b}$ & $-13.45 \pm 15.15$ & $-6.84 \pm 13.57$ & $-6.6 I \pm 14.63$ & $-10.40,-2.82$ & 0.0007 \\
\hline
\end{tabular}

Notes: Data are expressed as mean \pm SD. ${ }^{a}$ Change from baseline at Week 4; ${ }^{b}$ change from baseline at Week 8 ; *P-value by two-sample $t$-test. Abbreviations: HCTZ, hydrochlorothiazide; SD, standard deviation; siDBP, sitting diastolic blood pressure; siSBP, sitting systolic blood pressure. 
Table 3 Means of sitting diastolic and systolic blood pressure in nonresponders at Week 4 of high-dose treatment

\begin{tabular}{|c|c|c|}
\hline Visit & $\begin{array}{l}\text { Fimasartan/HCTZ } \\
(\mathrm{N}=74)\end{array}$ & $\begin{array}{l}\text { Fimasartan } \\
(\mathrm{N}=47)\end{array}$ \\
\hline \multicolumn{3}{|c|}{$\operatorname{siDBP}(\mathrm{mmHg})$} \\
\hline Week 4 & $97.93 \pm 5.64$ & $97.28 \pm 4.64$ \\
\hline Week 8 & $91.51 \pm 9.88$ & $93.64 \pm 8.26$ \\
\hline Change & $-5.72 \pm 9.34$ & $-3.64 \pm 6.97$ \\
\hline$P$-value ${ }^{\mathrm{a}}$ & $<0.0001$ & 0.0008 \\
\hline$P$-value ${ }^{b}$ & \multicolumn{2}{|c|}{0.1922} \\
\hline \multicolumn{3}{|c|}{ siSBP $(\mathrm{mmHg})$} \\
\hline Week 4 & $150.32 \pm 13.00$ & $|5| .34 \pm 9.28$ \\
\hline Week 8 & $142.46 \pm 16.64$ & $149.89 \pm 12.67$ \\
\hline Change & $-7.86 \pm 15.40$ & $-4.45 \pm 11.45$ \\
\hline$P$-value ${ }^{a}$ & $<0.0001$ & 0.0107 \\
\hline$P$-value ${ }^{b}$ & \multicolumn{2}{|c|}{0.1943} \\
\hline
\end{tabular}

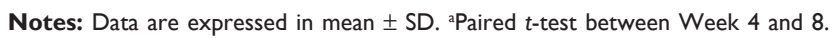
${ }^{b}$ Two-sample $t$-test of blood pressure change between groups.

Abbreviations: HCTZ, hydrochlorothiazide; SD, standard deviation; siDBP, sitting diastolic blood pressure; siSBP, sitting systolic blood pressure.

drugs was $11.79 \%$ (Table 4 ). The incidence of adverse events did not differ between the treatment groups. The most common adverse events were headache and dizziness. There was no statistically significant difference in the incidence of headache and dizziness between the treatment groups $(P=0.0698$ and 0.6568 , respectively). Among the other adverse events with an incidence of $<1 \%$, patients in the fimasartan group reported constipation, nausea, and palpitation. Patients in the fimasartan/HCTZ group reported chest discomfort, asthenia, pruritus, erectile dysfunction, and flushing sensations. There were no serious adverse events related to the study-drug treatment.

The incidence of significant changes in laboratory parameters was small. In both treatment groups, the elevation of aspartate transaminase or alanine transaminase in three patients was noted to be treatment related. The level of serum potassium increased to $5.3 \mathrm{mmol} / \mathrm{L}$ at Week 8 from $4.7 \mathrm{mmol} / \mathrm{L}$ at baseline and $4.3 \mathrm{mmol} / \mathrm{L}$ at Week 4 in a patient from the
fimasartan/HCTZ treatment group. The level of serum sodium decreased to $124 \mathrm{mmol} / \mathrm{L}$ at Week 8 , from $135 \mathrm{mmol} / \mathrm{L}$ at baseline, and $127 \mathrm{mmol} / \mathrm{L}$ at Week 4 in a patient from the fimasartan/HCTZ treatment group.

\section{Discussion}

As far as we are aware, this is the first study to have demonstrated that combination treatment with fimasartan and HCTZ is effective in the treatment of patients with essential hypertension who respond poorly to fimasartan monotherapy. Similar to the studies that evaluated combination ARB and HCTZ treatment, ${ }^{8,10,20,21}$ the combination treatment of fimasartan and HCTZ had better efficacy than fimasartan monotherapy. After 4 weeks of treatment, the combination of fimasartan and HCTZ was more effective in reducing siDBP and siSBP than fimasartan monotherapy. The difference in reduction of siDBP and siSBP between combination treatment and monotherapy was statistically significant $(P<0.05)$. The enhanced BP-lowering effect of combination therapy persisted over 8 weeks of treatment with optional dose escalation. The combination treatment showed a significantly higher responder rate at Weeks 4 and 8. Although not significant, the control rate of the combination treatment was higher than that of the monotherapy. The magnitude of BP lowering was comparable to other combination treatments of ARBs and HCTZ although they cannot be compared directly due to differences in study design., ${ }^{9,10,22}$ The difference in BP lowering between 8 weeks treatment of valsartan $160 \mathrm{mg}$ plus HTCZ $12.5 \mathrm{mg}$ and valsartan $160 \mathrm{mg}$ was approximately $2.0 \mathrm{mmHg}$ in siDBP and $3.7 \mathrm{mmHg}$ in siSBP. ${ }^{22}$ Combination olmasartan and HCTZ treatment also showed similar BP lowering compared to monotherapy (siDBP: $\sim 3.4 \mathrm{mmHg}$, siSBP: $\sim 5.3 \mathrm{mmHg}) .{ }^{10}$

In the current study, the difference in BP lowering after 4 weeks' treatment was $3.50 \mathrm{mmHg}$ in siDBP and $4.75 \mathrm{mmHg}$
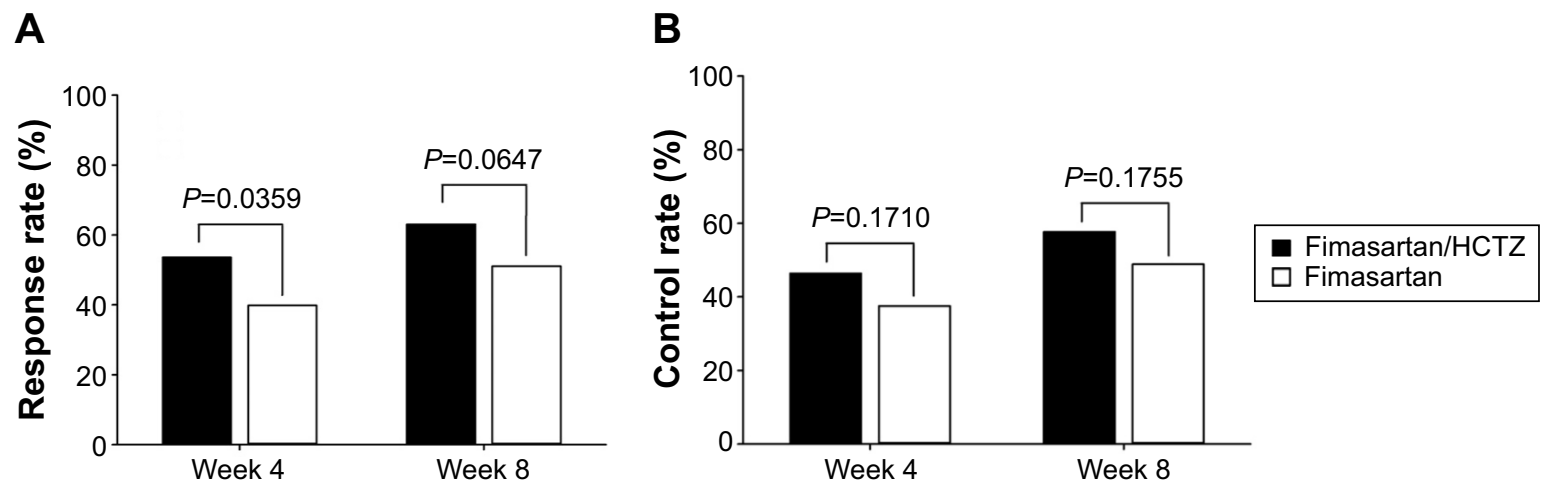

Figure 2 (A) Response and (B) control rate of fimasartan/hydrochlorothiazide (HCTZ) and fimasartan at Weeks 4 and 8 from baseline. 
Table 4 Drug-related adverse events with an incidence of $>1 \%$ in safety-analysis population

\begin{tabular}{|c|c|c|c|}
\hline \multirow{2}{*}{$\begin{array}{l}\text { Drug-related } \\
\text { adverse event }\end{array}$} & \multicolumn{3}{|c|}{ Number (\%) of subjects with ADRs } \\
\hline & $\begin{array}{l}\text { Fimasartan/HCTZ } \\
(\mathrm{N}=\mid 75)\end{array}$ & $\begin{array}{l}\text { Fimasartan } \\
(\mathrm{N}=\mathbf{8 8})\end{array}$ & $\begin{array}{l}\text { Total } \\
(N=263)\end{array}$ \\
\hline Total & $20(11.43)$ & II (12.50) & $31(11.79)$ \\
\hline$P$-value & & & 0.7993 \\
\hline Headache & $4(2.29)$ & $6(6.82)$ & $10(3.80)$ \\
\hline Dizziness & $8(4.57)$ & $3(3.4 I)$ & $9(3.42)$ \\
\hline
\end{tabular}

Abbreviations: $\mathrm{HCTZ}$, hydrochlorothiazide; ADRs, adverse drug reactions.

in siSBP. Fimasartan in combination with HCTZ was safe and well tolerated. The incidence of adverse events related to the study-drug treatment was small. There were no serious adverse events related to the study-drug treatment. The most frequent adverse events were headache and dizziness. The incidence did not differ between the treatment groups, and was also comparable to that reported in the previous Phase II and III studies of fimasartan. ${ }^{3,23}$ In terms of biochemical abnormalities, hypokalemia is a commonly associated biochemical abnormality of HCTZ. ${ }^{24,25}$ In the current study, no patient exhibited hypokalemia. It may be the addition of ARB which resulted in favorable effects regarding the biochemical abnormalities associated with HCTZ. Another biochemical abnormality associated with HCTZ is increase in triglyceride, ${ }^{26}$ which appeared in only one patient in the current study. Three patients experienced treatment-related elevation of liver enzyme after escalation of the fimasartan dose to $120 \mathrm{mg} /$ day. The elevated liver enzyme level in two patients returned to normal at the follow-up examination without intervention. The persistent elevation of liver enzyme in the remaining patient at the follow-up examination was concluded to be related to drinking alcohol. The elevation of liver enzyme at the higher dose is consistent with previous studies $^{3,4,23}$ and improved without intervention.

\section{Limitations}

A limitation of the current study is that a dose-dependent reduction in $\mathrm{BP}$ was not presented, because the study design did not aim at evaluating the dose-response relation. Despite this limitation, dose escalation of fimasartan/HCTZ to $120 \mathrm{mg} / 12.5 \mathrm{mg}$ or fimasartan $120 \mathrm{mg}$ in patients who did not achieve the target siDBP at Week 4 resulted in significant reductions in siDBP and siSBP at Week 8 , indicating a dose-dependent BP-lowering effect.

Another limitation is that the effect of combination treatment with HCTZ $25 \mathrm{mg}$ was not evaluated. Although several studies have shown that $25 \mathrm{mg}$ of HCTZ is more effective in lowering BP, we did not evaluate $\mathrm{HCTZ}$ at that dose because of potential biochemical abnormalities such as potassium depletion or uric acid elevation. ${ }^{8,9}$

\section{Conclusion}

The results of the current study suggest that combination treatment with fimasartan and HCTZ is effective in patients with hypertension which is not adequately controlled with fimasartan alone. The safety and tolerability of combination fimasartan and HCTZ treatment are comparable to those of fimasartan monotherapy.

\section{Disclosure}

This research was initiated and financially supported by Boryung Pharmaceutical Co, Ltd, Seoul, Republic of Korea. The sponsor supported the supply of the study drugs, laboratory testing, and data collection and analysis. All authors acted as principal investigators at the study sites, recruited patients, and collected data. The manuscript was prepared, reviewed, and approved by all authors prior to publication. The funding body was not involved in data analysis, data interpretation, or writing up of the results.

Dr Rhee has received lecture honoraria from Pfizer Inc, LG Life Sciences Ltd, and Bayer Korea Ltd, and research grants from Boryung Pharmaceutical Co, Ltd and Dong-A Pharmaceutical Co Ltd.

Dr Kim has received lecture honoraria from GlaxoSmithKline, Hanmi Pharmaceutical Co, Ltd, and research grant from Merck Sharp \& Dohme, LG Life Sciences Ltd, and Boryung Pharmaceutical Co, Ltd.

The authors have indicated that they have no other conflicts of interest with regard to the content of this article.

ClinicalTrials.gov identifier: NCT01258673.

\section{References}

1. Turnbull F; Blood Pressure Lowering Treatment Trialists' Collaboration. Effects of different blood-pressure-lowering regimens on major cardiovascular events: results of prospectively-designed overviews of randomised trials. Lancet. 2003;362(9395):1527-1535.

2. Kim TW, Yoo BW, Lee JK, et al. Synthesis and antihypertensive activity of pyrimidin-4(3H)-one derivatives as losartan analogue for new angiotensin II receptor type 1 (AT1) antagonists. Bioorg Med Chem Lett. 2012;22(4):1649-1654.

3. Lee SE, Kim YJ, Lee HY, et al; Investigators. Efficacy and tolerability of fimasartan, a new angiotensin receptor blocker, compared with losartan (50/100 mg): a 12-week, phase III, multicenter, prospective, randomized, double-blind, parallel-group, dose escalation clinical trial with an optional 12 -week extension phase in adult Korean patients with mild-to-moderate hypertension. Clin Ther. 2012;34(3):552-568.

4. Lee H, Kim KS, Chae SC, Jeong MH, Kim DS, Oh BH. Ambulatory blood pressure response to once-daily fimasartan: an 8-week, multicenter, randomized, double-blind, active-comparator, parallel-group study in Korean patients with mild to moderate essential hypertension. Clin Ther 2013;35(9):1337-1349. 
5. Olives C, Myerson R, Mokdad AH, Murray CJ, Lim SS. Prevalence, awareness, treatment, and control of hypertension in United States counties, 2001-2009. PLoS One. 2013;8(4):e60308.

6. Kim HJ, Kim Y, Cho Y, Jun B, Oh KW. Trends in the prevalence of major cardiovascular disease risk factors among Korean adults: results from the Korea National Health and Nutrition Examination Survey, 1998-2012. Int J Cardiol. 2014;174(1):64-72.

7. Dahlöf B, Sever PS, Poulter NR, et al; ASCOT Investigators. Prevention of cardiovascular events with an antihypertensive regimen of amlodipine adding perindopril as required versus atenolol adding bendroflumethiazide as required, in the Anglo-Scandinavian Cardiac Outcomes Trial-Blood Pressure Lowering Arm (ASCOT-BPLA): a multicentre randomised controlled trial. Lancet. 2005;366(9489):895-906.

8. Kochar M, Guthrie R, Triscari J, Kassler-Taub K, Reeves RA. Matrix study of irbesartan with hydrochlorothiazide in mild-to-moderate hypertension. Am J Hypertens. 1999;12(8 Pt 1):797-805.

9. McGill JB, Reilly PA. Telmisartan plus hydrochlorothiazide versus telmisartan or hydrochlorothiazide monotherapy in patients with mild to moderate hypertension: a multicenter, randomized, double-blind, placebocontrolled, parallel-group trial. Clin Ther. 2001;23(6):833-850.

10. Chrysant SG, Weber MA, Wang AC, Hinman DJ. Evaluation of antihypertensive therapy with the combination of olmesartan medoxomil and hydrochlorothiazide. Am J Hypertens. 2004;17(3):252-259.

11. Hughes AD. How do thiazide and thiazide-like diuretics lower blood pressure? J Renin Angiotensin Aldosterone Syst. 2004;5(4):155-160.

12. Coleman A, Freeman P, Steel S, Shennan A. Validation of the Omron 705IT (HEM-759-E) oscillometric blood pressure monitoring device according to the British Hypertension Society protocol. Blood Press Monit. 2006;11(1):27-32.

13. Gleim GW, Rubino J, Zhang H, et al. A multicenter, randomized, double-blind, parallel-group trial of the antihypertensive efficacy and tolerability of a combination of once-daily losartan $100 \mathrm{mg} /$ hydrochlorothiazide $12.5 \mathrm{mg}$ compared with losartan 100-mg monotherapy in the treatment of mild to severe essential hypertension. Clin Ther. 2006;28(10):1639-1648.

14. Flack JM, Saunders E, Gradman A, et al; Study Group for Losartan in African Americans with Hypertension. Antihypertensive efficacy and safety of losartan alone and in combination with hydrochlorothiazide in adult African Americans with mild to moderate hypertension. Clin Ther. 2001;23(8):1193-1208.

15. Ruilope LM, Simpson RL, Toh J, Arcuri KE, Goldberg AI, Sweet CS. Controlled trial of losartan given concomitantly with different doses of hydrochlorothiazide in hypertensive patients. Blood Press. 1996;5(1): $32-40$.
16. Sun NL, Zhu JR, Zhao Y, Tu YM; Co-Diovan Trial Investigators. Combination antihypertensive therapy with valsartan and hydrochlorothiazide in Chinese patients with mild-to-moderate hypertension. Curr Med Res Opin. 2008;24(10):2863-2871.

17. Bönner G; Multicentre Study Group. Antihypertensive efficacy and tolerability of candesartan-hydrochlorothiazide $32 / 12.5 \mathrm{mg}$ and $32 / 25 \mathrm{mg}$ in patients not optimally controlled with candesartan monotherapy. Blood Press Suppl. 2008;2:22-30.

18. Campbell M, Sonkodi S, Soucek M, Wiecek A. A candesartan cilexetil/ hydrochlorothiazide combination tablet provides effective blood pressure control in hypertensive patients inadequately controlled on monotherapy. Clin Exp Hypertens. 2001;23(4):345-355.

19. Sachse A, Verboom CN, Jäger B. Efficacy of eprosartan in combination with HCTZ in patients with essential hypertension. J Hum Hypertens. 2002;16(3):169-176.

20. MacKay JH, Arcuri KE, Goldberg AI, Snapinn SM, Sweet CS. Losartan and low-dose hydrochlorothiazide in patients with essential hypertension. A double-blind, placebo-controlled trial of concomitant administration compared with individual components. Arch Intern Med. 1996;156(3):278-285.

21. Benz JR, Black HR, Graff A, Reed A, Fitzsimmons S, Shi Y. Valsartan and hydrochlorothiazide in patients with essential hypertension. A multiple dose, double-blind, placebo controlled trial comparing combination therapy with monotherapy. J Hum Hypertens. 1998;12(12):861-866.

22. Mallion JM, Carretta R, Trenkwalder P, et al; Co-Diovan Study Group. Valsartan/hydrochlorothiazide is effective in hypertensive patients inadequately controlled by valsartan monotherapy. Blood Press Suppl. 2003;1:36-43.

23. Lee H, Yang HM, Lee HY, et al. Efficacy and tolerability of once-daily oral fimasartan 20 to $240 \mathrm{mg} / \mathrm{d}$ in Korean Patients with hypertension: findings from Two Phase II, randomized, double-blind, placebocontrolled studies. Clin Ther. 2012;34(6):1273-1289.

24. Morgan DB, Davidson C. Hypokalaemia and diuretics: an analysis of publications. Br Med J. 1980;280(6218):905-908.

25. Black HR. The evolution of low-dose diuretic therapy: the lessons from clinical trials. Am J Med. 1996;101(3A):47S-52S.

26. Kasiske BL, Ma JZ, Kalil RS, Louis TA. Effects of antihypertensive therapy on serum lipids. Ann Intern Med. 1995;122(2):133-141.

\section{Publish your work in this journal}

Drug Design, Development and Therapy is an international, peerreviewed open-access journal that spans the spectrum of drug design and development through to clinical applications. Clinical outcomes, patient safety, and programs for the development and effective, safe, and sustained use of medicines are a feature of the journal, which

\section{Dovepress}

has also been accepted for indexing on PubMed Central. The manuscript management system is completely online and includes a very quick and fair peer-review system, which is all easy to use. Visit http://www.dovepress.com/testimonials.php to read real quotes from published authors. 